\title{
OPTIMAL LYAPUNOV INEQUALITIES FOR BOUNDARY VALUE PROBLEMS
}

\author{
Antonio Cañada, Salvador Villegas
}

Abstract. This work is devoted to review some recent results on $L_{p}$ Lyapunov-type inequalities $(1 \leqslant p \leqslant \infty)$ for resonant differential equations. In the case of Ordinary Differential Equations, we consider Neumann boundary conditions and an explicit optimal result is obtained. Moreover, it is also treated the case in which the resonance appears at higher eigenvalues. We also study mixed boundary conditions. From this study, and under some natural restrictions on the linear coefficient, the relation between Neumann boundary conditions and disfocality arises in a natural way. For Partial Differential Equations it is proved that the relation between the quantities $p$ and $N / 2$ plays a crucial role in order to obtain $L_{p}$ Lyapunov-type inequalities, for resonant linear problems with Neumann boundary conditions on a bounded domain $\Omega \subset \mathbb{R}^{N}$. This fact shows a deep difference with respect to the ordinary case. Combining these linear results with Schauder fixed point theorem, we can obtain some new results about the existence and uniqueness of solutions for resonant nonlinear problems. Finally, we comment some conclusions on systems of equations.

Mathematics subject classification (2000): 34B05, 34B15, 35J25, 35J65.

Keywords and phrases: Linear boundary problems, Lyapunov inequalities, ordinary differential equations, partial differential equations, nonlinear resonant problems.

\section{REFERENCES}

[1] P. W. BATES, Solutions of nonlinear elliptic systems with meshed spectra, Nonlinear Anal., 4 (1979), $1023-1030$.

[2] R.C. BRown And D.B. Hinton, Lyapunov inequalities and their applications, Survey on Classical Inequalities, T.M. Rassias, ed. Kluwer, Dordrecht, 2000, 1-25.

[3] A. CAÑAda, J.A. Montero AND S. Villegas, Liapunov-type inequalities and Neumann boundary value problems at resonance, Mathematical Inequalities and Applications, 8 (2005), 459-476.

[4] A. CAÑADA, J.A. Montero AND S. VILLEgAs, Lyapunov inequalities for partial differential equations, J. Funct. Anal., 237, (2006), 176-193.

[5] A. CAÑADa AND S. VIllegas, Optimal Lyapunov inequalities for disfocality and Neumann boundary conditions using $L^{p}$ norms, Discrete Contin. Dyn. Syst. 20 (2008), 877-888.

[6] A. CAÑADA AND S. VIllegas, Lyapunov inequalities for Neumann boundary conditions at higher eigenvalues, to appear in J. Eur. Math. Soc. (JEMS).

[7] A. CaÑADa AND S. VIllegas, Matrix Lyapunov inequalities for ordinary and elliptic partial differential equations, preprint.

[8] G. Croce And B. Dacorogna, On a generalized Wirtinger inequality, Discrete and Continuous Dynamical Systems, 9, (2003), 1329-1341.

[9] B. Dacarogna,W. Gangbo and N. Subía, Sur une généralisation de l'inégalité de Wirtinger, Ann. Inst. Henri Poincaré, Anal. Non Linéaire, 9, (1992), 29-50.

[10] C.L. DolPH, Nonlinear integral equations of Hammerstein type, Trans. Amer. Math. Soc., 66, (1949), 289-307.

[11] D. G. DE FigueIREDo, The Dirichlet problem for nonlinear elliptic equations: a Hilbert space approach, Partial differential equations and related topics, Lecture Notes in Math. 446, Springer Verlag, (Berlin 1975), 144-165. 
[12] B.J. HARRIS, On an inequality of Lyapunov for disfocality, J. Math. Anal. Appl., 146, (1990), 495500.

[13] P. Hartman, Ordinary Differential Equations, John Wiley and Sons Inc., New York-London-Sydney, 1964.

[14] W. Huaizhong AND L. Yong, Neumann boundary value problems for second-order ordinary differential equations across resonance, SIAM J. Control and Optimization, 33, (1995), 1312-1325.

[15] J. L. KAZDAN AND F. W. WARner, Remarks on some queasilinear elliptic equations, Comm. Pure Appl. Math. 28, (1975), 567-597.

[16] L. Kotin, A generalization of Liapunov's inequality, J. Math. Anal. Appl., 102, (1984), 585-598.

[17] M.K. Kwong, On Lyapunov's inequality for disfocality, J. Math. Anal. Appl., 83, (1981), 486-494.

[18] A.M. LyAPUNOv, Sur une série relative a la théorie des équations différentielles linéaires avec coeficient périodiques, C.R. Acad. Sci. Paris, 123 (1896), 1248-1252.

[19] J. MAWHIN AND J.R. WARD,Nonuniform nonresonance conditions at the two first eigenvalues for periodic solutions of forced Liénard and Duffing equations, Rocky Mountain J. Math., 12, (1982), 643-654.

[20] J. MaWhin AND J.R. WARD, Periodic solutions of some forced Liénard differential equations at resonance, Arch. Math (Basel), 41, (1983), 337-351.

[21] J. MAWHIN AND J.R. WARD, Nonresonance and existence for nonlinear elliptic boundary value problems, Nonlinear Anal., 5 (1981), 677-684.

[22] J. MAWHin, J.R. WARD AND M. WILlem, Variational methods and semilinear elliptic equations, Arch. Rational Mech. Anal., 95, (1986), 269-277.

[23] E.R. VAN KAMPEN AND A. WINTNER, On an absolute constant in the theory of variational stability, Amer. J. Math., 59 (1937), 270-274.

[24] L. YONG AND W. HUAIZHONG, Neumann problems for second order ordinary differential equations across resonance, Z. Angew Math. Phys. 46, (1995), 393-406.

[25] M. ZHANG, Certain classes of potentials for p-Laplacian to be non-degenerate, Math. Nachr., 278, (2005), 1823-1836. SI. 